employment and income, housing and basic services, social security and access to malaria prevention measures. Data were analysed using SPSS version 17.0.

Results 115 cases and 63 controls were interviewed. Income $<1$ USD per day, $<3$ years of school, marital status single, single-parent family, without social security and no bed-nets in house were not associated to malaria in pregnancy in bivariate analysis $(\mathrm{p}>0.05)$. Pregnant women who had a farmer as a family member (OR 2.39, $95 \%$ CI 1.12 to 5.13 ), bodies of water around the house (OR $4.66,95 \%$ CI 2.24 to 9.66), house roof made of palm tree leaves (OR 2.45, 95\% CI 1.16 to 5.15 ) were more likely to have had malaria in multivariate analysis.

Conclusion In rural areas of Colombia where poverty is very common quality of house and access to basic public services explain better social differences of pregnant women that are related with malaria frequency.

\section{SP5-14 A STUDY TO DETERMINE THE KNOWLEDGE AND PRACTICE OF FOOT CARE IN PATIENTS WITH CHRONIC DIABETIC ULCERS}

doi:10.1136/jech.2011.142976p.50

\begin{abstract}
${ }^{1,2} \mathrm{C}$ V M Jinadasa, ${ }^{*}{ }^{1} \mathrm{M}$ Jeewantha. ${ }^{1}$ Faculty of Medicine University of Colombo, Colombo, Sri Lanka; ${ }^{2}$ Sri Jayawardhanapura Hospital, Colombo, Sri Lanka
\end{abstract}

Introduction Diabetic foot ulcers account for many hospital admissions and is a major cause of amputations. This is preventable by effective identification, education and preventive foot care practice. Objective Determine the level of knowledge and practice of foot care among patients with chronic diabetic foot ulcers.

Methodology Individuals with diagnosed diabetic foot ulcers $(n=110)$ were selected from National Hospital of Sri Lanka for this descriptive study. They were given an interviewer administered, pretested questionnaire. Patient perceptions of foot care were enquired. A scoring system ranging from 0 to 10 was employed to analyse the responses given for level of knowledge and practice of diabetic foot care.

Results Mean age was 58.4 years (SD \pm 8.6 ) and $57.3 \%$ were males. Non-healing ulcers were present among $82.7 \%$ and amputations amounted to $38.2 \%$. The control of diabetes was poor in $60 \%$. Regarding foot care knowledge, the mean score was $8.37,75.5 \%$ had scored above mean and $52.7 \%$ were aware of all principles of foot care. Regarding foot care practices, the mean score was $4.55,47.3 \%$ participants had scored below mean and $22.7 \%$ did not practice any foot care principle and hence scored 0 . A Statistically significant difference exists between the foot care knowledge and practice scores $(p<0.001, z=-8.151) .51 \%$ have not been educated prior to the occurrence of complications.

Conclusion Results demonstrate a satisfactory knowledge on diabetic foot care but practices of preventive techniques were unsatisfactory. Good patient follow-up to increase compliance would help to improve this situation.

\section{SP5-15 "KNOWLEDGE-ACTION GAP" AMONG BANGLADESHI TYPE 2 DIABETIC SUBJECTS}

doi:10.1136/jech.2011.142976p.51

${ }^{1} \mathrm{~F}$ Saleh, ${ }^{*}{ }^{1} \mathrm{~F}$ Ara, ${ }^{2} \mathrm{~F}$ Khan, ${ }^{3} \mathrm{~L}$ Ali. ${ }^{1}$ Department of Community Nutrition, Bangladesh Institute of Health Sciences (BIHS), Dhaka, Bangladesh; ${ }^{2}$ DCT, Sanofi-aventis Bangladesh Ltd, Dhaka, Bangladesh; ${ }^{3}$ Department of Biochemistry \& Cell Biology, Bangladesh Institute of Health Sciences (BIHS), Dhaka, Bangladesh

Introduction The association of knowledge against actual practice has not been properly investigated in the BIRDEM (a tertiary care hospital of BADAS). The aim of this study was to assess the level of knowledge about type 2 diabetes mellitus (T2DM) and to see the association between knowledge and action among T2DM patients.

Methods An analytical cross-sectional design. A total of 500 patients withT2DM (M 58\%, age $49.4 \pm 8.8$ years) were selected from the outpatient department. Knowledge score was categorised as poor $(<45 \%)$, fair $(45-60 \%)$ and good $(>60 \%)$ on the basis of education criteria in our 10th and 12 th grade public examinations.

Results The levels of knowledge were poor in $45 \%$, fair in $47 \%$ and good in $9 \%$ of the study subjects. Only $12 \%$ subjects had good level of $\mathrm{HbA1c}$. Among them the levels of knowledge were poor in $44 \%$, fair in $48 \%$ and good in $8 \%$. About $24 \%$ subjects belonged to fair HbA1c level and the levels of knowledge were poor in 39\%, fair in $52 \%$ and good in $9 \%$ among these subjects. More than half of the subjects $(64 \%)$ had poor glycaemic status. In this group the levels of knowledge were poor in $46 \%$, fair in $45 \%$ and good in $9 \%$. A significant negative association was found between total knowledge score and HbA1c level $(r=-0.08, p=0.05)$.

Conclusion There is a knowledge-action gap in Bangladeshi T2DM subjects which may indicate largely ineffective education programs. Patient empowerment may facilitate better control of diabetes.

\section{SP5-16 TOWARDS INTEGRATION OF UNCONVENTIONAL MEDICINES IN THE PUBLIC HEALTH SERVICE: THE EXPERIENCE OF ROHINGYA REFUGEES' IN BANGLADESH}

doi:10.1136/jech.2011.142976p.52

${ }^{1,2} \mathrm{~A} \mathrm{H}$ Mollik, ${ }^{*} \mathrm{~K}$ Akter, ${ }^{2} \mathrm{~N}$ K Azam, ${ }^{3} \mathrm{~F}$ B Hossain, ${ }^{4} \mathrm{H}$ Rahman, ${ }^{5} \mathrm{~K}$ B T M Chowdhury, ${ }^{6} \mathrm{D}$ Sen, ${ }^{2} \mathrm{R}$ McField. ${ }^{1}$ Peoples Integrated Alliance, Dhaka, Bangladesh; ${ }^{2}$ Practical Academy on Wise Education and Research Foundation, Dhaka, Bangladesh; ${ }^{3}$ South Asian Women's Rights Organization, Scarborough, Ontario, Canada; ${ }^{4}$ Stamford University Bangladesh, Dhaka, Bangladesh; ${ }^{5}$ Biogene Life Care, Dhaka, Bangladesh; ${ }^{6}$ State College of Health Sciences, Dhaka, Bangladesh

Introduction Bangladesh hosts more than 200000 Rohingya refugees from Myanmar. With no changes inside Myanmar in sight, Bangladesh must come to terms with the long-term needs of all the Rohingya refugees' in the country, and allow international organisations to expand services that benefit the Rohingya refugees as well as local communities. We therefore conducted a survey of plants used by the traditional healers in the Rohingya refugees' of Bangladesh.

Methods In-depth information regarding plants type, preparation of medicines, ailments for which they are used, dosages, and side effects if any, were obtained from the traditional healers. Plant samples were collected, and identified at the Bangladesh National Herbarium.

Results A total of 13 plants were collected, which were used to treat common ailments like coughs, colds, fevers, and dermatitis infections as well as a number of other diseases like gastritis, epilepsy, gynaecology, and hepatitis. The plant names obtained in our survey included Nigella sativa L., Arachis hypogaea L., Asteracantha longifolia Nees., Gendarussa vulgaris Nees., Brassica napus L., Vitex negundo L., Clerodendrum indicum (L.) Kuntze, Achyranthes aspera L., Wedelia chinensis (Osbeck) Merr., Melia azadirachta L., Paederia foetida L., Swertia chirata (Wall.) C. B. Clarke, and Colocasia esculenta (L.) Schott.

Conclusion Since the Rohingya refugees' patients appeared to be generally satisfied with the treatment offered through these plants, they do not have to visit modern medical practitioners. It is important to conduct proper scientific studies towards discovery of compounds of interest in these plants, which can be used as safe and effective medicines. 